\title{
The Effects of Short-Term Exercise on Anthropometric Measurements
}

\author{
Tanya DOMINA**a ${ }^{a}$ Patrick KINNICUTT ${ }^{a}$ \\ ${ }^{a}$ Central Michigan University, Mt. Pleasant (MI), USA
}

\begin{abstract}
Currently in the United States, one in four adults is considered either overweight or obese and efforts are underway by U.S. government agencies and health professionals to encourage adults to take control of their health status; including more exercise and dietary changes. In response, a new exercise program called "boot camp" has been introduced in communities across the U.S. The boot camps are a series of short-term programs 4 weeks in duration and are modeled after military basic training for new recruits, or boot camp. During these four weeks, participants undergo a rigorous cardiovascular, weight training and dietary program. For this study, 62 subjects participated in a series of boot camps in Mount Pleasant, Michigan, USA. These subjects, in coordination with the boot camp instructor, were body scanned before and after completing the program. This allowed the participants to determine where anthropometric changes occurred in their somatotypes. This paper discusses the temporal changes in anthropometric measurements obtained from a 3D body scanner and a medical-grade scale as a result of a rigorous exercise and dietary program. Of the 74 subjects, 5 were male and 69 were female, and ages ranged from 18 to 58 at the time of the boot camp program. Pre-program BMIs for female subjects ranged from 19.5 to 41.1 and for male participants 26.2 to 32.4 . The female subjects lost an average of 2.5 kilograms during the 4 week period, while males lost an average of 5.4 kilograms. On average, the female subjects lost $2.54 \mathrm{~cm}$ and men lost $4.1 \mathrm{~cm}$ in belly circumference. Pre- versus post-body scanning results indicated that the change in belly circumference is correlated with the change in BMI for both genders $(r=0.46$ for females, $r=0.75$ for males). This paper presents the protocol and other statistics describing how the results of changes in somatotypes as a result of an exercise program can be captured by body scanning technology. In addition, this paper explores how people attempting to alter their body shape, such as professional athletes gaining weight or persons in weight loss programs, can measure their progress from the scans. 3D body scans may be much more affirming and motivating to an individual trying to reduce or reshape their body, especially when weight stays the same or is slow to change.
\end{abstract}

Keywords: $3 d$ body scanning, exercise anthropometric

\section{Introduction}

Currently in the United States, one in four adults are considered either overweight or obese and efforts are underway by U.S. government agencies and health care practitioners to encourage adults to take control of their health status and regular exercise is an integral component of health promotion campaigns. In fact as early as 1999, the U.S. Center for Disease Control (CDC) stated that a primary environmental factor responsible for much of the chronic disease in the U.S. is physical inactivity [1]. Evidence clearly shows that regular physical exercise improves physiological and psychological health [2]. For the majority of the people having a sedentary job, the recommended increase in general physical activity can be achieved by exercise, sport, recreation, and life-style activities [3].

\subsection{Anthropometric assessment}

Anthropometry, or the study of human body measurements, began in 1870 when Quelet attempted to obtain measurements of the average man in order to provide better fitting uniforms for Napoleon's army [4]. However, anthropometry did not become a recognized discipline until the 1950's [5] with researchers utilizing tape measure, weight scale, spreading caliper and sliding compass as measurement tools. These methods of studying anthropometry were subject to both unreliability of the measures $[5,6,7,8,9]$ and observer error. Over the past 70 years of anthropometric research, observer error has proven to be the most problematic, even by trained observers $[10,11,12]$. Observer error includes inaccurate instrument placement and readings, subject stance, and imprecise placement of landmark location.

Although many studies are conducted to promote and understand the benefits of physical activity, measurement limitations plague these studies, owing to concerns about validity from participant 
reports and weaknesses in translation of laboratory measures to field settings, contributing to poor ecological validity [13]. The traditional means of assessing where weight has been lost and muscle gained is through use of a tape measure. To collect changes in circumference measurements, a tape measure is routinely used; however, as an instrument of measure it may be subject to human error $[14,15]$. Maylia [16] utilized a tape measure to measure thigh circumference. Measurements were taken by seven trained observers on three subjects at two different intervals. Results showed that tape measure error for each experiment varied among subjects with differences over 1.3 inches noted. This lack of consistency when tape measurements are used was highlighted by Fairclough [17] who demonstrated that observers failed to notice an increase of 1.2 inches when measuring waist girth of the same subject with a tape measure. The severity of tape measurement error is likely compounded when measurements are taken in the field and with untrained fitness instructors or by the individual themselves. Regardless of who is taking the measurements, variables that must be considered when collecting circumference measurements with a tape measure are that the individual should be trained in positioning the subject, obtaining repeated measurements in the same location using body landmarks, keeping the tape measure parallel to the body, evenly distributing the tape, asking the subject not to inhale or exhale too intensely, not to stoop etc. [18]. Overall, the traditional method of collecting anthropometric changes is time-consuming, fraught with observer errors and inaccuracies, and requires physical touching of the subject.

The development of 3D laser scanning has solved many of the aforementioned problems allowing for the extraction of precise body measurements from scan data in seconds [19]. Previous research indicates that the data generated from a body scanner is sufficiently accurate to be used as an anthropometric measurement tool [20]. Heuberger [21] sought to determine if a 3D body scanner provided more accurate circumference measurements than those collected from a traditional tape measure. Results indicated that significant differences existed between circumference measurements calculated by the body scanner and those which were gathered from a tape measure. Examination of the mean circumferences of hip and waist as collected by a tape measure was one inch smaller on average than the mean of the hip and waist obtained from the body scanner generated measurements. In addition, the circumferences varied between successive measurements using the tape measure within and between interviewers. This research was substantiated by Lu \& Wang [22] who found that the precision of the scan-derived measurements was better than that of the manual measurements which were significantly different than then those from the 3D scanner.

\subsection{Boot Camp}

Initially modeled after military basic training for new recruits, or boot camp, fitness boot camp was first introduced sometime in the early 2000 s and has since spread to communities across the U.S. Generally the term "boot camp" is used to describe a four to eight week outdoor fitness program that incorporates endurance and resistance exercise as well as dietary restraints [23]. Frequently done in a combination of individual effort and team setting, boot camps typically incorporate elements of cooperation and competition to complete tasks. Boot camps can be focused on a particular demographic group, health concern, or desired anthropometric change or can be general enough to attract a wide variety of participants, all with different needs. Similarly, boot camp participants enroll in a fitness boot camp program for a variety of reasons, but weight loss and/or to increase strength and endurance are cited as the most common reasons.

While there is a tremendous body of scholarly research on the physiological and psychological benefits of exercise, few studies have focused attention on commercial weight loss and fitness programs. Curves International is the largest fitness franchise in the world, attracting a wide variety of women. The fitness program focuses on both physical exercise and regulation of caloric intake and has been the focus of several research studies $[24,25,26,27,28]$. These studies have found that regular participation in resistance-based circuit exercise program resulted in a significant loss of body mass and improvements body composition and overall fitness. Founded in 1963, Weight Watchers is a weight loss program that primarily focuses on restricting caloric intake, but also promotes the benefits of regular physical exercise on health and weight loss [29]. In a two year study, Heshka [30] examined the effectiveness of the commercial weight loss program. The participants were required to follow dietary restrictions and an activity plan that was based upon the current U.S. National Institutes of Health guidelines. Results indicated only a modest reduction in weight, but waist circumference was reduced by about $4.5 \mathrm{~cm}$ at year 1 and $2.5 \mathrm{~cm}$ at the end of year 2 [30]. 
Research on the benefits of a boot camp fitness program is sparse and what research has been published focuses primarily on military personnel $[31,32,33]$. While the Internet is filled with websites where boot camp fitness instructors and participants have anecdotal accounts of increased physical fitness and weight loss, virtually no scholarly research exists that examines the efficacy of a fitness boot camp program. Therefore, the purpose of this research was to assess temporal changes in anthropometric measurements of boot camp fitness participants obtained from a 3D body scanner.

\section{Method}

The subjects were recruited through the boot camp fitness instructor and their participation was voluntary. At the beginning of boot camp, each subject was scanned utilizing a Human Solutions VITUS/smart 3D body scanner. For accuracy, each subject was minimally clothed in form fitting garments such as bra and underwear, briefs, bicycle shorts or swimsuit. Subjects were then weighed and asked to fill out a standard demographic and exercise frequency questionnaire. At the completion of the four week boot camp fitness program, the subjects were again body scanned and weighed. This allowed the participants to determine where anthropometric changes occurred in their somatotypes. Lastly, the subjects' information was entered into a non-personalizable database and the data was analyzed.

\section{Test/Data}

For this study, data was collected from 79 subjects who were participating in a series of boot camps in Mount Pleasant, Michigan, USA. Tables 1 and 2 present a summary of the demographic, weight change and anthropometric changes of the boot camp participants. The majority of the subjects were female $(92 \%)$ and between $18-58$ years old $(M=38)$. Their average pre- boot camp weight was 71.60 $\mathrm{kg}$ and average post-weight was $69.13 \mathrm{~kg}$, with an average weight loss of $2.47 \mathrm{~kg}$. Male subjects were between 35-47 years of age, reported an average pre- boot camp weight of $90.42 \mathrm{~kg}$, an average post-weight of 85.35 , and an average weight loss of $5.07 \mathrm{~kg}$ (Table 1$)$.

Table 1. Demographics and weight data for boot camp participants.

\begin{tabular}{|c|l|r|r|}
\hline \multicolumn{4}{|c|}{ Boot Camp Demographic Statistics } \\
\hline \multirow{4}{*}{ Age (yrs) } & & Males & Females \\
\cline { 2 - 4 } & Count & 6 & 73 \\
\cline { 2 - 4 } & PreWeight (kg) & 90.42 & 71.60 \\
\cline { 2 - 4 } & PostWeight (kg) & 85.35 & 69.13 \\
\hline \multirow{4}{*}{ Weight Loss (kg) } & Average & 39 & 38 \\
\cline { 2 - 4 } & Min & 35 & 18 \\
\cline { 2 - 4 } & Max & 47 & 58 \\
\cline { 2 - 4 } & Mverage & 5.07 & 2.47 \\
\cline { 2 - 4 } & Max & 1.81 & -1.81 \\
\hline
\end{tabular}

Examination of circumference data (Table 2) indicates that both male and female boot camp participants realized a decrease in the anthropometric measurements collected for this study. Additionally, both male and female boot camp participants experienced the largest circumference decrease in the belly girth $(-3.64 \mathrm{~cm}$ and $-2.58 \mathrm{~cm}$ respectively), followed by buttock girth for women $(-2.14 \mathrm{~cm})$ and chest girth for men $(-1.65 \mathrm{~cm})$. Only male boot camp participants realized on average a circumference increase, for both the neck girth $(+.10 \mathrm{~cm})$ and the arm girth $(+.28 \mathrm{~cm})$. As a result of the boot camp, the measured BMI dropped on average among both male and female subjects. The males appeared to have a larger average BMI reduction ( 1.63 for males versus 0.90 for females), but since the male sample size was small $(M=6)$, the standard deviation was larger. 
Table 2. BMI and circumference measurements for boot camp participants.

\begin{tabular}{|c|c|c|c|c|c|c|c|}
\hline \multicolumn{8}{|c|}{ Measurement Statistics } \\
\hline \multicolumn{2}{|c|}{ Before Boot Camp } & \multirow{2}{*}{\begin{tabular}{|l|} 
Male \\
25.95
\end{tabular}} & \multirow{2}{*}{$\begin{array}{r}\text { Female } \\
19.44\end{array}$} & \multicolumn{2}{|c|}{ After Boot Camp } & \multirow{2}{*}{$\begin{array}{l}\text { Male } \\
24.62 \\
\end{array}$} & \multirow{2}{*}{\begin{tabular}{|r} 
Female \\
19.44
\end{tabular}} \\
\hline \multirow{3}{*}{ Pre BMI } & Min & & & \multirow{3}{*}{ Post BMI } & Min & & \\
\hline & Average & 28.73 & 26.05 & & Average & 27.10 & 25.15 \\
\hline & Max & 31.87 & 41.10 & & Max & 29.87 & 38.88 \\
\hline \multirow{3}{*}{$\begin{array}{c}\text { Pre Belly } \\
\text { Circumference } \\
(\mathrm{cm})\end{array}$} & Min & 89.51 & 67.23 & \multirow{3}{*}{$\begin{array}{c}\text { Post Belly } \\
\text { Circumference } \\
\text { (cm) }\end{array}$} & Min & 82.55 & 67.26 \\
\hline & Average & 100.66 & 92.32 & & Average & 97.02 & 89.74 \\
\hline & Max & 110.69 & 119.08 & & Max & 108.03 & 115.37 \\
\hline \multirow{3}{*}{$\begin{array}{l}\text { Pre Buttock Girth } \\
\qquad(\mathrm{cm})\end{array}$} & Min & 98.63 & 86.28 & \multirow{3}{*}{$\begin{array}{l}\text { Post Buttock Girth } \\
\qquad(\mathrm{cm})\end{array}$} & Min & 99.64 & 86.49 \\
\hline & Average & 104.95 & 106.03 & & Average & 103.39 & 103.89 \\
\hline & Max & 109.30 & 135.10 & & Max & 107.44 & 132.23 \\
\hline \multirow{3}{*}{$\begin{array}{l}\text { Pre Thigh Girth } \\
\qquad(\mathrm{cm})\end{array}$} & Min & 54.38 & 48.46 & \multirow{3}{*}{$\begin{array}{l}\text { Post Thigh Girth } \\
\text { (cm) }\end{array}$} & Min & 53.26 & 49.28 \\
\hline & Average & 59.09 & 60.06 & & Average & 57.99 & 59.04 \\
\hline & Max & 65.38 & 76.58 & & Max & 63.47 & 73.33 \\
\hline \multirow{3}{*}{$\begin{array}{l}\text { Pre Bust/Chest } \\
\text { Girth }(\mathrm{cm})\end{array}$} & Min & 97.99 & 81.89 & \multirow{3}{*}{$\begin{array}{l}\text { Post Bust/Chest } \\
\text { Girth (cm) }\end{array}$} & Min & 94.46 & 81.74 \\
\hline & Average & 110.02 & 98.81 & & Average & 108.37 & 98.15 \\
\hline & Max & 119.79 & 122.20 & & Max & 117.98 & 120.65 \\
\hline \multirow{3}{*}{$\begin{array}{c}\text { Pre Neck } \\
\text { Diameter (cm) }\end{array}$} & Min & 13.00 & 10.06 & \multirow{3}{*}{$\begin{array}{c}\text { Post Neck } \\
\text { Diameter (cm) }\end{array}$} & Min & 13.08 & 2.34 \\
\hline & Average & 13.67 & 13.24 & & Average & 13.77 & 12.44 \\
\hline & Max & 14.99 & 21.49 & & Max & 14.71 & 17.81 \\
\hline \multirow{3}{*}{ Pre Arm Girth $(\mathrm{cm})$} & Min & 29.01 & 23.44 & \multirow{3}{*}{$\begin{array}{l}\text { Post Arm Girth } \\
\text { (cm) }\end{array}$} & Min & 28.14 & 24.03 \\
\hline & Average & 30.98 & 29.78 & & Average & 31.26 & 29.19 \\
\hline & Max & 34.26 & 37.77 & & Max & 33.68 & 36.93 \\
\hline
\end{tabular}

Pearson correlation coefficients were calculated comparing the losses for each measurement with each other for the female participants (Table 3). The male correlation coefficients showed similar results, but since the sample size $(M=6)$ was so small those results are not presented here. As Table 3 shows, there was little or no correlation between the neck diameter loss and loss from other parts of the body. The loss in belly circumference as a result of the boot camp showed a weak positive correlation to the loss in the buttock girth, the total weight loss and the BMI reduction. The thigh girth reduction had an even stronger positive correlation to weight loss and BMI reduction then the belly circumference loss. As expected, the total weight loss and the corresponding BMI reduction were strongly positively correlated. 
Table 3. Pearson Correlation Coefficients Comparing Measurement Losses Among Females

\begin{tabular}{|l|l|l|l|l|l|l|l|l|}
\hline & Neck & Belly & $\begin{array}{c}\text { Bust/ches } \\
\text { t girth }\end{array}$ & $\begin{array}{c}\text { Thigh } \\
\text { girth }\end{array}$ & $\begin{array}{c}\text { Buttock } \\
\text { girth }\end{array}$ & $\begin{array}{c}\text { Upper } \\
\text { arm } \\
\text { girth }\end{array}$ & $\begin{array}{c}\text { Weight } \\
\text { Loss }\end{array}$ & $\begin{array}{c}\text { BMI } \\
\text { Diff }\end{array}$ \\
\hline $\begin{array}{l}\text { Neck } \\
\text { Diameter }\end{array}$ & 1.00 & & & & & & & \\
\hline $\begin{array}{l}\text { Belly } \\
\text { circumference }\end{array}$ & -0.22 & 1.00 & & & & & & \\
\hline $\begin{array}{l}\text { Bust/chest } \\
\text { girth }\end{array}$ & -0.07 & 0.14 & 1.00 & & & & & \\
\hline $\begin{array}{l}\text { Thigh } \\
\text { girth }\end{array}$ & -0.05 & 0.19 & 0.49 & 1.00 & & & & \\
\hline $\begin{array}{l}\text { Buttock } \\
\text { girth }\end{array}$ & -0.02 & 0.46 & 0.04 & 0.15 & 1.00 & & & \\
\hline $\begin{array}{l}\text { Upper arm } \\
\text { girth }\end{array}$ & -0.07 & -0.01 & 0.05 & 0.14 & 0.23 & 1.00 & & \\
\hline $\begin{array}{l}\text { Weight } \\
\text { Loss }\end{array}$ & -0.17 & 0.44 & 0.38 & 0.62 & 0.33 & 0.12 & 1.00 & \\
\hline $\begin{array}{l}\text { BMI } \\
\text { Reduction }\end{array}$ & -0.14 & 0.44 & 0.39 & 0.62 & 0.36 & 0.16 & 0.99 & 1.00 \\
\hline
\end{tabular}

An ANOVA analysis was performed on the female subjects comparing the pre- and post- BMIs as a result of the boot camp (Table 4). Again, the males showed similar results but the sample size was too small so the data is not presented here. As Table 4 shows, while the BMI averages are lower for the females post-BMI, the difference in the means is not statistically significant.

Table 4. ANOVA Analysis of Female BMIs Pre- and Post- Boot Camp

\begin{tabular}{|l|r|r|r|r|r|r|}
\hline \multicolumn{1}{|c|}{ SUMMARY } & & & & & & \\
\hline PreBMI & Count & \multicolumn{1}{c|}{ Sum } & Average & Variance & & \\
\hline PostBMI & 73 & 1901.70 & 26.05 & 16.65 & & \\
\hline & 73 & 1836.24 & 25.15 & 14.69 & & \\
\hline ANOVA & & & & & & \\
\hline Source of Variation & SS & $d f$ & MS & $F$ & P-value & F crit \\
\hline Between Groups & 29.35 & 1 & 29.35 & 1.87 & 0.17 & 3.91 \\
\hline Within Groups & 2256.50 & 144 & 15.67 & & & \\
\hline & & & & & & \\
\hline Total & 2285.8531 & 145 & & & & \\
\hline
\end{tabular}

\section{Results}

The data presented in Section 3 shows that while it appears that the boot camp may have played a role in subjects losing weight and losing fat around their belly and other parts of their body, the results are not statistically significant. The data also indicates that the loss of circumference in the upper thigh (hypothesized to be from a loss of fat in the upper thigh region) appears to have the highest correlation to BMI loss.

The use of the body scanner to compute these measurements showed that while for this particular set of boot camp subjects statistically significant weight loss did not occur, it did show that the use of the body scanner could be used to determine differences in somatotypes in a longitudinal study. It also shows that the loss of fat or geometry varies from individual to individual, with significant loss in the belly, buttock and upper thigh regions as a result of boot camp activities. 


\section{Conclusion}

Preliminary research indicated that the body scanner was able to identify any changes in circumference for the boot camp fitness participants. More importantly, it was able to detect very small changes in circumferences, such the average increase in the men's neck and arm girths; changes that likely would not have been captured by tape measure. Additionally, this study provides a procedure for using the body scanner as an accurate anthropometric measurement tool for health and fitness instructors to determine how and where an individual may temporally change in somatotype as a result of a fitness program. In sum, utilization of the body scanner shows tremendous promise as a health and fitness tool. In the future, the body scanner may introduce the next generation of anthropometric evaluation. Much more accurate and detailed changes in body size and shape can be measured with body scanning technology and people attempting to alter their body shape, such as professional athletes gaining altering muscle mass or persons in weight loss programs, can measure their progress from the scans.

\section{References}

1. Koplan, J. P. and Dietz, W. H., (1999): "Caloric imbalance and public health policy", JAMA, Vol. 282, pp. 1579-1581.

2. U.S. Dept. of Health and Human Services, (2000): "Healthy People 2010", US Dept. of Human Services, Washington, DC.

3. Van Etten, L. M. L. A., Westerterp, K. R., Verstappen, F. T. J., Boon, B. J. B., Saris, W. H. M., (1997): "Effect of an 18-wk weight-training program on energy expenditure and physical activity", Journal of Applied Physiology, Vol. 82, pp. 298-304.

4. CUErgo Cornell University Ergonomics Website (accessed 2011): http://ergo.human.cornell.edu/DEA 325 notes/anthropometry.html.

5. Simmons, K. P. and Istook, C. L., (2003): "Body measurement techniques: Comparing 3D body scanning and anthropometric methods for apparel applications", Journal of Fashion Marketing and Management, Vol. 7, pp. 306-332.

6. Bray, G. A., Greenway, F. L., Molitch, M. E., (1978): "Use of anthropometric measures to access weight loss", American Journal of Clinical Nutrition, Vol. 31, pp. 769-73.

7. Cameron, N., (1986): "The methods of auxological anthropology", In Faulkner, F., and Tanner, J. M. (Eds.), Human Growth. 3rd edition, Plenum Press, New York, NY, pp. 3-46.

8. Foster, T. A., Webber. L. S., Sathanur, R., (1980): "Measurement error in a large-scale anthropometric survey", American Journal of Biology, Vol. 4, pp. 253-63.

9. Johnston, F.E., Hamill, P.V. V., Lemshow, S., (1972): "Skinfold Thickness of Children 6-11 Years, United States", Vital and Health Statistics, Series 11, No. 120, US Department of Health and Human Services, Washington DC.

10. Bennett, K. A. and Osborne, R. H., (1978): "Interobserver measurement reliability in anthropometry", Human Biology, Vol.39, pp. 124-30.

11. Gordon, C. C. and Bradtmiller, B., (1992): "Inter-observer error in a large-scale anthropometric survey", American Journal of Human Biology, Vol. 4, pp.253-63.

12. Jamison, P. L. and Zegura, S. L., (1974): "A univariate and multivariate examination of measurement error in anthropometry", American Journal of Physical Anthropology, Vol.40, pp. 197-203.

13. Layne, C. S., Mama, S. K., Banda, J. A., Lee, R. E., (2011): "Development of an ecologically valid approach to assess moderate physical activity using accelerometry in community dwelling women of color: A cross-sectional study", International Journal of Behavioral Nutrition and Physical Activity, Vol. 8, No. 21, pp. 1-7.

14. Schreiner, P. J., Pitkaniemi, J., Pekkanen, J., Salomaa, V. V., (1995): "Reliability of near-infrared interactance body fat assessment relative to standard anthropometric techniques", Journal of Clinical Epidemiology, Vol. 48, pp. 1361-1367.

15. Sonnenschein, E. G., Kim, M. Y., Pasternack, B. S., Toniolo, P. G., (1993): "Sources of variability in waist and hip measurements in middle aged women", American Journal of Epidemiology, Vol. 138, pp. 301-309.

16. Maylia, E., Fairclough, J. A., Nokes, L. D. M., Jones, M. D., (1999): "Can thigh girth be measured accurately? A preliminary investigation", Journal of Sport Rehabilitation, Vol. 8, pp. 43-49.

17. Fairclough, J. A., Mintowt-Czyz, W. J., Mackie, I., Nokes, L., (1994): "Abdominal girth: An unreliable measure of intra-abdominal bleeding". Injury, Vol. pp. 16, 85-87. 
18. Wells, J. C. K., Treleaven, P., Cole, T. J., (2007): "BMI compared with 3-dimensional body shape: The UK National Sizing Survey", American Journal of Clinical Nutrition, Vol. 85, pp. 419-425.

19. Lerch, T., MacGillivray, M., Domina, T., (2007): "3D Laser Scanning: A Model of Multidisciplinary Research", Journal of Textiles and Apparel Technology and Management, Vol.5, No. 4, pp. 1-22.

20. Lin, J. D., Chiou, W. K., Weng, H. F., Fang, J. T., Liu, T. H., (2004): "Application of three-dimensional body scanner: Observation of prevalence of metabolic syndrome", Clinical Nutrition, Vol. 23, pp. 1313-1323.

21. Heuberger, R., Domina, T., MacGillivray, M., (2008): "Body scanning as a new anthropometric measurement tool for health-risk assessment", International Journal of Consumer Studies, Vol. 32, No. 1, pp. 34-40.

22. Lu, J.-M. and Wang, M.-J., J., (2010): "The evaluation of scan-derived anthropometric measurements", IEEE Transactions on Instrumentation and Measurement, Vol. 59, No. 8, pp. 2048-2054.

23. Quelh, F. (2007): "How to succeed at the business of boot camp" IDEA Fitness Journal, April, pp. 38-46.

24. Kerksick, C., Thomas, A., Campbell, B., Taylor, L., Wilborn, C., Marcello, B., Roberts, M., Pfau, E., Grimstvedt, M., Opusunju, J., Magrans-Courtney, T., Rasmussen, C., Wilson, R., Kreider, R. B., (2009): "Effects of popular exercise and weight loss program on weight loss, body composition, energy expenditure and health in obese women", Nutrition \& Metabolism, Vol. 6, No. 23, pp. 1-17.

25. Kerksick, C. M., Wismann, J., Fogt, D., Thomas, A., Taylor, L., Campbell, B., Wilborn, C., Harvey, T., Roberts, M., La Bounty, P., Galbreath, M., Marcello, B., Rasmussen, C., Kreider, R., (2010): "Changes in weight loss body composition and cardiovascular disease risk after altering macronutrient distributions during a regular exercise program in obese women", Nutrition Journal, Vol. 9, No. 59, pp

26. Kreider, R. B., Serra, M., Beavers, K. M., Moreillon, J., Kresta, J. Y., Byrd, M., Oliver, J. M., Gutierrez, J., Hudson, G., Deike, E., Shelmadine, B., Leeke, P., Rasmussen, C., Greenwood, M., Cooke, M., Kerksick, C., Campbell, J. K., Beiseigel, J., Jonnalagadda, S. S., (2011): "A structured diet and exercise program promotes favorable changes in weight loss, body composition, and weight maintenance", Journal of the American Dietetic Association, Vol. 111, No. 6, pp. 828-43.

27. Kreider, R. B., Rasmussen, C., Kerksick, C. M., Wilborn, C., Taylor, L., Campbell, B., Magrans-Courtney, T., Fogt, D., Ferreira, M., Li, R., Galbreath, M., losia, M., Cooke, M., Serra, M., Guitierez, J., Byrd, M., Kresta, J. Y., Simbo, S., Oliver, J., Greenwood, M., (2011): "A carbohydrate-restricted diet during resistance training promotes more favorable changes in body composition and markers of health in obese women with and without insulin resistance", The Physician and Sportsmedicine, Vol. 39, No. 2, pp. 1-18.

28. Magrans-Courtney, T., Wilborn, C., Rasmussen, C., Ferreira, M., Greenwood, L., Campbell, B., Kerksick, C., Nassar, E., Li, R., losia, M., Cooke, M., Dugan, K., Willoughby, D., Soliah, L., Kreider, R. B., (2011): "Effects of diet type and supplementation of glucosamine, chondroitin, and MSM on body composition, functional status, and markers of health in women with knee osteoarthritis initiating a resistance-based exercise and weight loss program", Journal of the International Society of Sports Nutrition, Vol., 8, No. 8, pp. 1-17.

29. Weight Watchers "Fitness \& Health" (accessed 2011): www.weightwatchers.com.

30. Heshka, S., Anderson, J. W., Atkinson, R. L., Greenway, F. L., Hill, J. O., Phinney, S. D., Kolotkin, R. L., Miller-Kovach, K., Pi-Sunyer, F. X., (2003); "Weight loss with self-help compared with a structured commercial program: A randomized trial", The Journal of the American Medical Association, Vol. 289, No. 14, pp. 1792-1798.

31. Riley, D. J., Windgard, D., Morton, D., Nichols, J., Ming, S. R., Macera, C., (2005): "Use of self-assessed fitness and exercise parameters to predict objective fitness", Medicine \& Science in Sports \& Exercise, Vol. 37, No. 5, pp. 827-831.

32. Yanovich, R., Evans, R., Israeli, E., Constantini, N., Sharvit, N., Merkel, D., Epstein, Y., Moran, D. S., (2008): "Differences in physical fitness of male and female recruits in gender-integrated army basic training", Medicine \& Science in Sports \& Exercise, Vol. 40, No. Suppl., pp. S654-659.

33. Harman, E. A., Gutekunst, D. J., Nindl, P. N., Bradley, C., Alemany, J. A., Mello, R. P., Sharp, M. A., (2008): "Effects of two different eight-week training programs on military physical performance", Journal of Strength \& Conditioning Research, Vol. 22, No. 2, pp. 524-534. 